\title{
Determination of Bumper Styling and Engineering Parameters to Reduce Pedestrian Leg Injuries
}

\author{
Peter J. Schuster (US) and Bradley Staines (UK) \\ Ford Motor Company
}

Copyright (C) 1998 Society of Automotive Engineers, Inc.

\begin{abstract}
The European Commission is proposing legislation aimed at reducing the severity of injuries sustained by pedestrians in the event of an impact with the front-end of a motor vehicle. One aspect of this proposed legislation is reducing the pedestrian's leg injuries due to contact with the bumper and frontal surfaces of a vehicle, assessed using a 'pedestrian leg impact device,' or 'leg-form.'
\end{abstract}

This proposed legislation presents the challenge of designing a bumper system which achieves the required performance in the leg-form impact-without sacrificing the bumper's primary function of vehicle protection during low-speed impacts. The first step in meeting this challenge is to understand what effects the front-end geometry and stiffness have on the leg-form impact test results. These results will then need to be compared to low-speed impact performance to assess if the two requirements are compatible.

This paper describes an investigation-using concept Finite Element models and a front-end variable geometry vehicle test buck - of the styling and engineering tradeoffs for a pedestrian safe bumper system.

\section{INTRODUCTION}

Over the past three decades, car manufacturers and legislators have worked diligently to enhance the safety of vehicle occupants. As a direct result of this effort, the number and severity of automotive accidents resulting in injury to the occupants is on the decline.

One area of automotive safety that has received less attention, however, is the protection of pedestrians. While research into pedestrian accidents began in the late 1970 's, it was not until recently that considerable effort has been focused on developing a vehicle performance requirement. In 1990, the $\mathrm{EC}^{(\text {a) }}$ commissioned a group of

${ }^{a}$ EC: European Commission (provides overall policy direction to each of its 12 member states).
European automotive safety agencies (TRL ${ }^{(b)}$, INRETS $^{(c)}$, $\mathrm{BASt}^{(\mathrm{d})}$, and $\mathrm{TNO}^{(\mathrm{e})}$ - the EEVC ${ }^{(1)}$ Working Group 10) to develop a pedestrian impact test procedure that was both repeatable and accurate; replicating a typical pedestrian impact event. The group's original proposals were published in 1991 [1]. These consisted of three subsystem impact test procedures targeted at further reducing the severity of leg, thigh / pelvis, and head injuries (the three most commonly injured areas in a pedestrian impact) at velocities up to $40 \mathrm{~km} / \mathrm{h}(25 \mathrm{mph})$. The test procedures were proposed as a draft EC Directive in February, 1996 [2]. In addition, these test procedures are being used to evaluate vehicles in the new Euro-NCAP(9) test program sponsored by the U.K. DoT ${ }^{(m)}$, FiA ${ }^{(1)}$, SNRA $^{(0)}$, et al.

The three impact modes presented in the EEVC proposals are (Figure 1):

1. Leg impacts to the vehicle's bumper system and frontal surfaces using a 'free-flight' pedestrian leg impactor (a 'leg-form') [3].

2. Thigh impacts to the vehicle's hood/bonnet leading edge with a guided thigh impact device [4].

3. Adult and child head impacts to the vehicle's hood-top with two free-flight head impact 'head-forms' [5].

This paper reviews some of the results of an investigation of the styling and engineering implications of the proposed leg impact requirements. In this test procedure, a leg

\footnotetext{
- TRL: Transport Research Laboratory (U.K.)

'INRETS: Institut National de Recherche sur les Transports el Leur Sécurité (National Institute for Transport and Safety Research, France)

¿ BASt: Bundesanstalt für Straßenwesen (Federal Highway Research Institute, Germany)

- TNO: Toegepast Natuurwentenschapppelijk Ondersek (Netherlands Organization for Applied Scientific Research)

'EEVC: European Experimental Vehicles Committee 9 NCAP: New Car Assessment Program

"DoT: Department of Transport

' FiA: Federation Internationale de L'Automobile

' SNRA: Swedish National Road Administration
} 

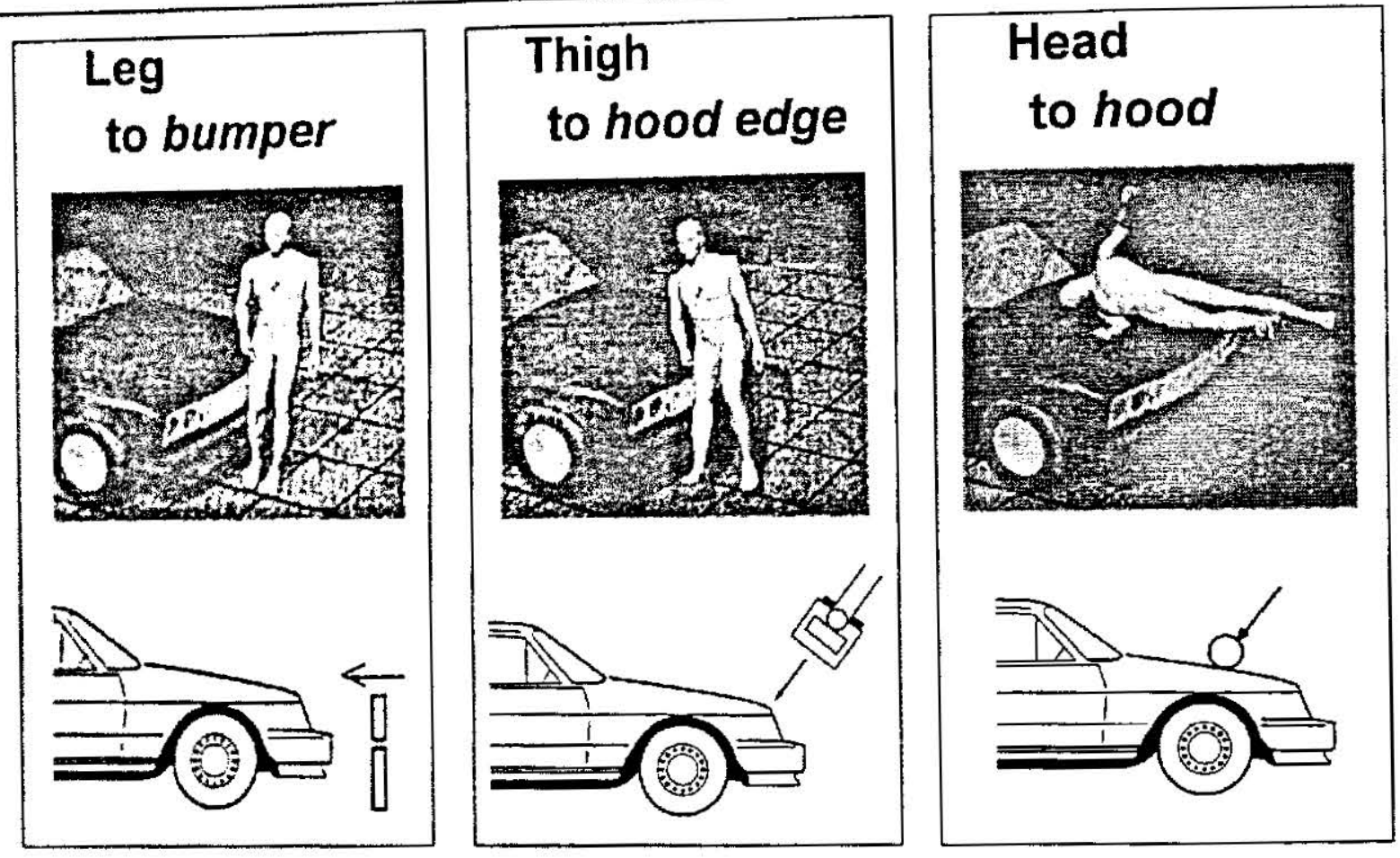

Figure 1: EEVC WG10 Proposed Impact Modes

impactor (a detailed discussion of this device is included in the "Leg-Form Impactor" section of this paper) is propelled at a stationary vehicle at a velocity of $40 \mathrm{~km} / \mathrm{h}$ (approximately $25 \mathrm{mph}$ ). The velocity is parallel to the longtudinal axis of the vehicle and can be performed at any point actoss the tront face between the 'vehicle cornets' For this impact event, the proposed performance requirements are:

- Tibla Acceleration (near knee) $<150 \mathrm{~g}$

- Lateral Knee Bend Angle < 15 degrees

- Lateral Knee Shear Deformation < $6 \mathrm{~mm}$

\section{BACKGROUND}

The bumper system has the largest influence on the vehicle's leg impact performance, with the hood leading edge playing a secondary role in limitation of knee bending. Many of the previous papers on this subject are very generic in nature. stating which bumper parameters infuence the leg impact performance. In addition, most of the priot work has not used one of the current leg-form
umpactors.

This eartier work, however, has been essential in the development and implementation of the current test series. in particulat. much of the prior work $(6-16]$ has made general recommendations for bumper design which were included in the basic designs tested:

- Lower bumper height-to-ground has been projected to reduce lateral knee bend angle $[6,7,8,9,10,11,12]$, while potentialy increasing head impact speed [13].
- A structural lower stiffener $[13,14,15]$ has been proposed as an alternative to a lower bumper height.

- A compliant (soft) bumper system [16] has been used to reduce tibia acceleration, but may reduce vehicle low-speed damage protection.

In order to minimize the influence on (a) the vehicle's styling and (b) the ECE-42 [17] (low-speed damageability) performance, bumper heights should be maintained. Because of this, a structural lower stiffener was added below the existing bumper to reduce lateral knee bend angles. Bumper height-to-ground variation was limited to $+1-25 \mathrm{~mm}$.

Although a very compliant (hollow) bumper system has been shown [16] to perform well in the pedestrian leg impact, this would result in poor performance in the ECE42 test. Because of this, the following adaptation of a typical bumper system design was chosen as the preferred solution:

- Rigid bumper beam or lower cross-member

- Locally compliant energy-absorbing foam

- Flexible plastic fascia

- Structural lower stiffener

In addition to selection of the bumper system configuration, information on the specific shape and stiffness of these components is also required. The focus of this study was to develop a better understanding of which shape and stiffness characteristics are beneficial to leg-form impact performance. 


\section{VARIABLE FRONT-END BUCK}

The shape (geometry) and stiffness of a vehicle's frontend are the most significant contributors to pedestrian legform impact performance. In order to investigate the specific effects of each characteristic, an adjustable parameterized vehicle front-end design was needed. In particular, the ability to change the bumper (foam) and lower stiffener dimensions, locations, and stiffnesses was required.

To this end, a 'Variable Front-End Buck' which represents the front-end design of a typical European passenger car was developed. It included a bumper, grille, hood/bonnet, and lower stiffener (added below the bumper beam and foam). The buck allowed front-end shape (geometry) and engineering (stiffness) design characteristics to be changed between tests. It represented a $600 \mathrm{~mm}$ section across a vehicle front-end (ignoring any curvature). A diagram of the buck (Figure 2) identifies the adjustable geometry and stiffness factors. Table 1 provides a definition of each of the factors.

The design of the Buck was significantly influenced by the

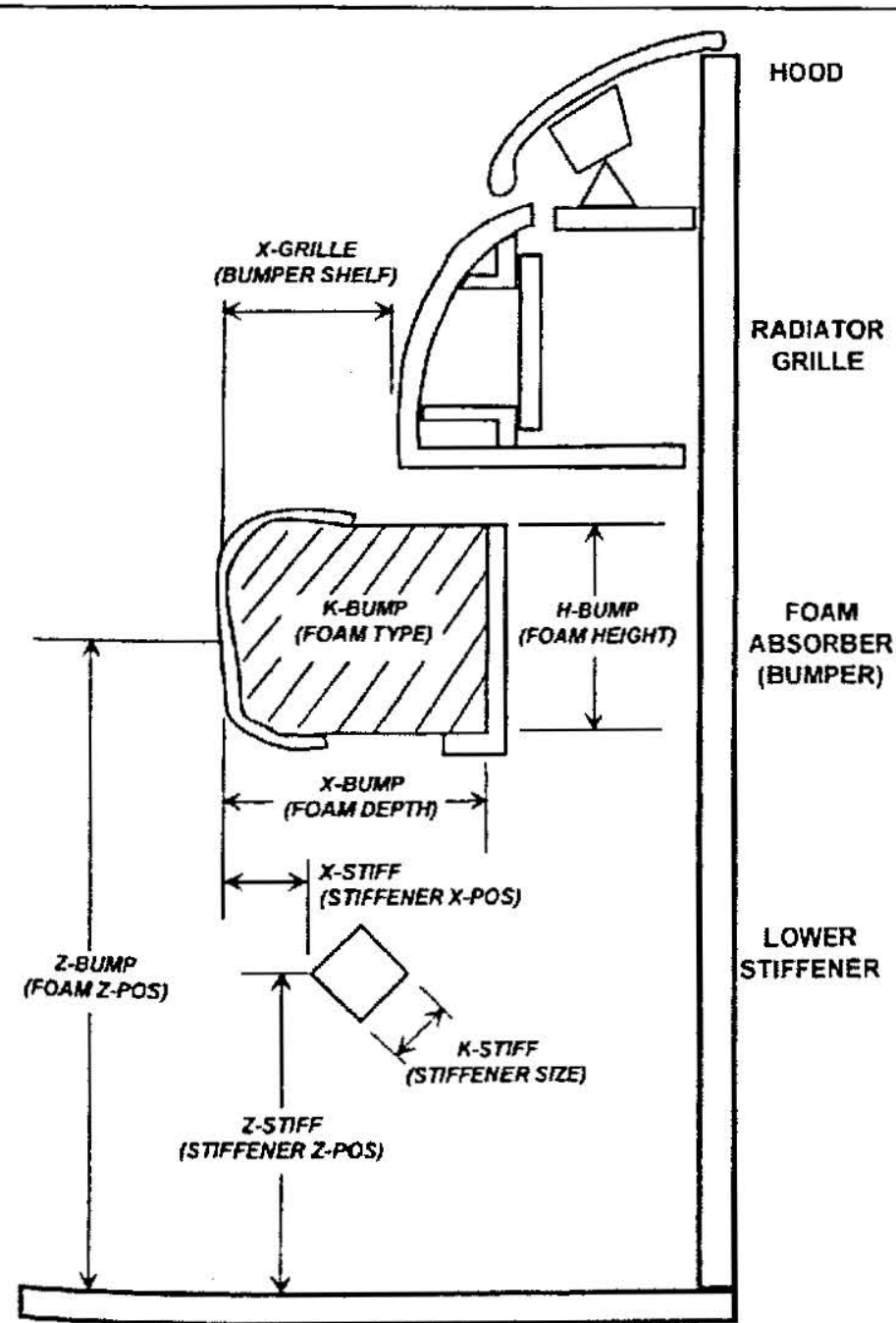

Figure 2: Variable Front-End Buck
Table 1: Front-End Buck Adjustable Factors

\begin{tabular}{|l|c|}
\hline Factor & Description \\
\hline X-grille & $\begin{array}{c}\text { Longitudinal distance from the leading } \\
\text { edge of the bumper to the grille. }\end{array}$ \\
\hline H-bump & Vertical height of bumper foam. \\
\hline K-bump & $\begin{array}{c}\text { Plateau stress (at } 40 \% \text { deflection) of the } \\
\text { PU foam when impacted at } 4 \mathrm{~km} / \mathrm{h} .\end{array}$ \\
\hline X-bump & Longitudinal depth of the bumper foam. \\
\hline Z-bump & $\begin{array}{c}\text { Vertical distance from the ground to the } \\
\text { center of the bumper foam. }\end{array}$ \\
\hline K-stiff & $\begin{array}{c}\text { Average load for first } 75 \text { mm of stiffener } \\
\text { stroke. Related to stiffener size. }\end{array}$ \\
\hline X-stiff & $\begin{array}{c}\text { Longitudinal distance from the bumper } \\
\text { leading edge to the stiffener leading edge. }\end{array}$ \\
\hline Z-stiff & $\begin{array}{c}\text { Vertical distance from the ground to the } \\
\text { center of the stiffener. }\end{array}$ \\
\hline
\end{tabular}

$C A E^{(a)}$ Concept Model development and the results of the CAE DOE ${ }^{\text {(b) }}$ (see CAE APPROACH, below). The CAE Concept Model development process identified how and where to attach components. It also indicated that the lower stiffener should have a 'diamond-shaped' crosssection to provide for uniform collapse during the impact. The CAE model also showed that the flexible fascia over the bumper foam influenced the way the foam absorbed energy.

The CAE DOE provided an initial indication of which factors were most important to pedestrian leg-form impact performance. These factors were then included in the Buck testing. In addition, the CAE DOE showed that the lower stiffener sizes initially selected (see Table 3 ) were too far apart (this factor overwhelmed the others in the DOE). Because of this, different sizes were chosen during the Variable Front-End Buck testing (see Table 5).

\section{LEG-FORM IMPACTOR}

Pedestrian leg impact performance is assessed through the use of a 'leg-form' impactor. The impactor is constructed from two steel tubular structures (the 'femur' and 'tibia') with prescribed masses, centers of gravity, and moments of inertia. These structures are joined by a knee joint allowing two degrees-of-freedom-lateral knee bending' and 'lateral knee shear;' hereafter referred to as simply 'bend' and 'shear.' The entire impactor is wrapped

${ }^{\text {a }} \mathrm{CAE}$ - Computer-Aided Engineering, including Finite Element Analysis (FEA).

${ }^{-}$DOE - Design of Experiments: A formal process for designing an experiment to get the most information from the least amount of tests. The experimental designs used in this work are more closely associated with Taguchi DOE method than Classical DOE. 


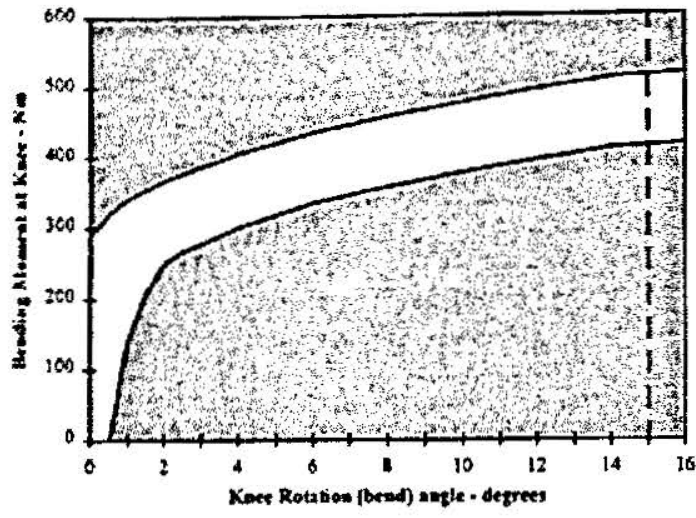

(a)

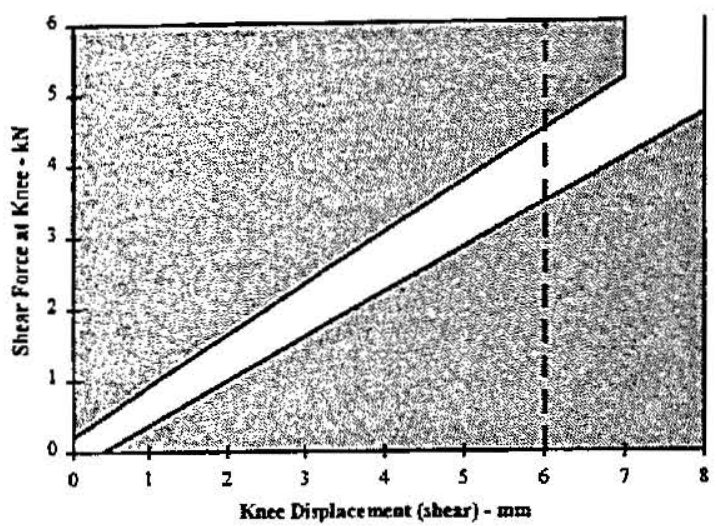

(b)

Figure 3: Knee Certification Corridors

in $25 \mathrm{~mm}$ of Confor ' 'flesh' foam and $6 \mathrm{~mm}$ of Neoprene 'skin.'

The characteristics of the knee in shear and bend are specified in terms of quasi-static force-displacement corridors, shown in Figure 3. Note that these tolerance bands are quite wide, especially for quasi-static certification tests. This is particularly true for bend, where the non-linear relationship between bending load and angle (the metric) exaggerates variability in the measured response. The full certification procedures can be found in the drath regulatory document [2].

Initial prototype leg-form ligament designs, as proposed by INRETS [3], attempted to satisfy both requirements by using a pair of metal non-linear 'ligaments' able to deform in both bend and shear modes. Il was soon noted that this design suffered instability of the ligament when subjected to bend, and metric 'cross-talk ${ }^{\text {ial }}$ between bend and shear. As a consequence of this. TRL proposed an alternative design in 1995 for the leg-form which separated the bend and shear mechanisms, allowing each to act independently. This solved the instability issues asscciated with the INRETS design and simultaneously reduced cross-talk [18]. The bend characteristics continued to be simulated through the use of non-linear ligaments, with the shear compliance achieved through the use of a linear shear spring.

The TRL design has a new concern not seen in the INRETS design-because the shearing displacement is controlled by an elastic spring. the femur and tibia segments can oscillate relative to each other. This 'shear resonance' not only affects the measurement of shear in the knee. but atso the acceleration at the top of the tibia segment $T R L$ is in the process of revising the design to
eliminate this concern

Because of this uncertainty, neither design was used in

"Cross-talk: The measurement of one objective

datum affects the value obtained for another. this investigation. Instead, a MIRA ${ }^{(0)}$-developed hybrid design, internally known as the 'Simplified Leg-Form,' was used. This has approximately the same mass distribution and bending characteristics as is specified in the EEVC test procedure [1]. However, a shearing mechanism is not included in the design due to the concerns outlined above. It is the opinion of the authors that any system which meets the bend and acceleration requirements would require few changes to also meet the shear requirement.

Comparisons between the mass properties and bending characteristics of the Simplified Leg-Form and the EEVC proposal are shown in Table 2 and Figure 4. While these differences may change the magnitudes of the individual test results, it is the authors' opinion that the trends in the responses will be consistent. Because of this, the bend and acceleration results will only be reported relative to the overall average of the test results.

Table 2: Leg-Form Mass Properties

\begin{tabular}{|c|c|c|c|c|}
\hline \multirow{2}{*}{} & \multicolumn{2}{|c|}{ EEVC Proposal } & \multicolumn{2}{c|}{ Simplified Leg-form } \\
\cline { 2 - 5 } & FEMUR & TIBIA & FEMUR & TIBIA \\
\hline mass $(\mathrm{kg})$ & 8.6 & 4.8 & 8.2 & 5.0 \\
\hline $\mathrm{I}^{(\mathrm{c})}\left(\mathrm{kg}-\mathrm{m}^{2}\right)$ & 0.127 & 0.120 & 0.104 & 0.100 \\
\hline $\mathrm{CG}^{(\mathrm{c})}(\mathrm{mm})$ & 217 & 233 & 228 & 186 \\
\hline
\end{tabular}

\section{CAE APPROACH}

To help shorten product development cycles, a CAE model for the leg impactor and a vehicle modeling methodology have been developed. In addition, these tools were used to determine the initial design for the Variable Front End Buck. All analyses presented in this

\footnotetext{
'MIRA: Motor Industry Research Association (U.K.)

'I: Moment of inertia about the center of gravity

${ }^{\circ} \mathrm{CG}$ : Distance from knee center to Center of Gravity
} 


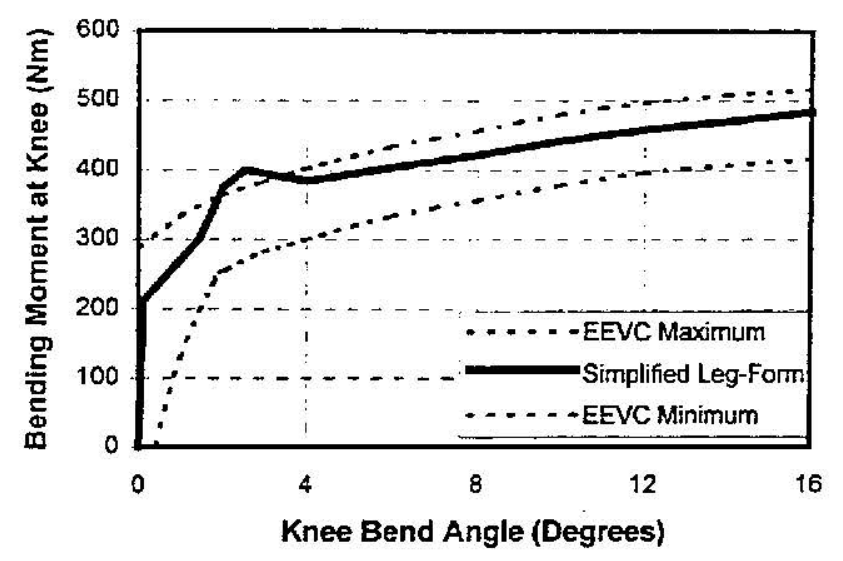

Figure 4: Leg-Form Knee Bend Characteristics

paper have been performed with RADIOSS ${ }^{(a)}$ version $3.1 \mathrm{H}$ or later on a Cray C9O.

\section{DESCRIPTION OF MODEL.}

The simplified impactor was modeled with only nine basic parts (Figure 5). They were:

- Femur and Tibia Skins (rubber)

- Femur and Tibia Flesh (foam)

- Femur and Tibia Cores

- Femur and Tibia Rigid Bodies

- Knee Spring

Since this model does not include shear at the knee, a very simple knee model definition was applied. First, the fermur and tibia segments were modeled full-length (eliminating the gap between the tibia and femur segments). Knee rotation was then allowed by specifying no interfaces between these two segments in the model. The segments were joined at the center by a zero-length general spring element.

All degrees-of-freedom for the spring element were constrained with the exception of lateral bending. For this degree-of-freedom, a non-linear function was used to define the bending properties of the knee. Isotropic hardening was used to represent the behavior of the physical knee ligaments, based on the leg impactor static bending certification corridor.

Figure 6 shows the finite element representation of the variable geometry buck. It includes a foam block supported rigidly at its rear face, a bumper fascia to correctly simulate the distribution of force and energy into the foam, and a lower stiffener. In addition, a grill and hood leading edge are included to correctly support the upper portion of the leg during the later stages of the impact.

The Grille, Fascia and Stiffener are all modeled using material Type 2 (elastic-plastic). The foam is modeled using material Type 33 (low density viscoelastic-plastic foam) based on material properties, supplied by Bayer AG, from dynamic crush tests at $4 \mathrm{~km} / \mathrm{h}$. The viscous nature of polyurethane (PU) foams however, means that the properties are often significantly different at higher impact velocities such as the $40 \mathrm{~km} / \mathrm{hr}$ used in pedestrian leg impact tests. For this reason the supplied data was arbitrary scaled, based on previous high speed PU foam testing experience.

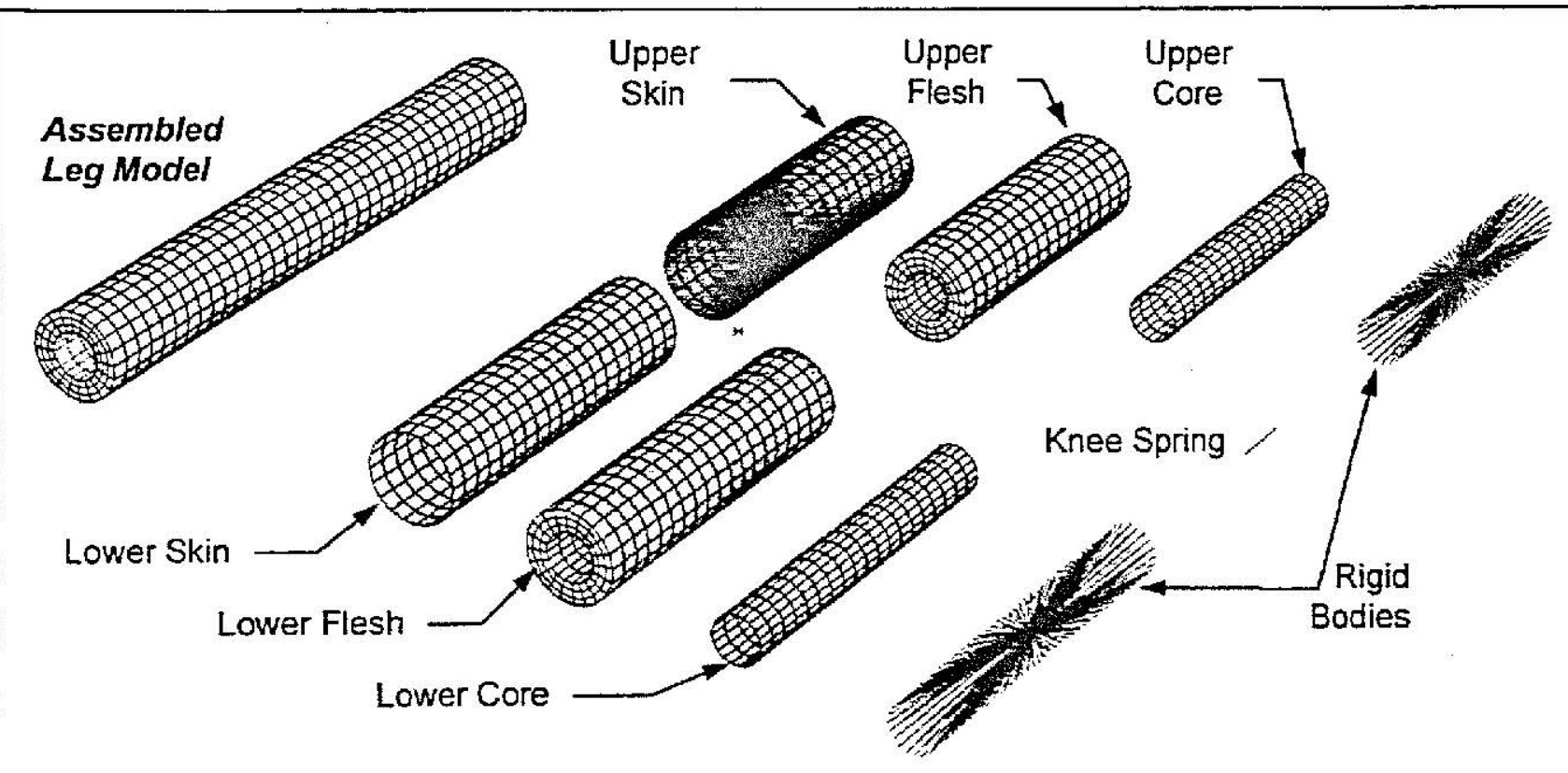

Figure 5: CAE Leg Impactor Model Construction 


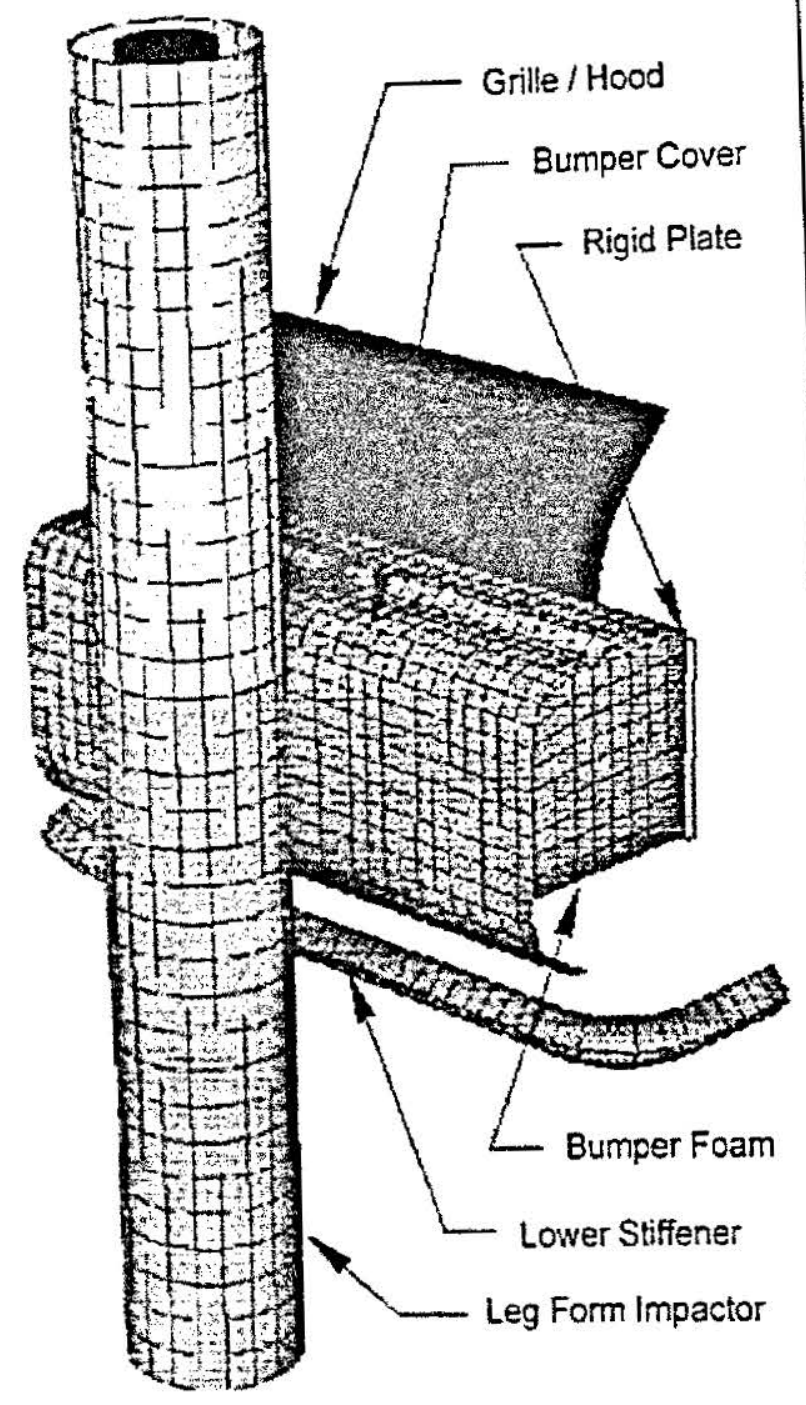

Figure 6: CAE Concept Model

\section{ANALYTICAL PROCEDURE}

In crder to minimize the number of CAE runs required and to maximize the lessons learned from them, a DOE approach was chosen. Of the eight parameters listed in Table 1. the four deemed to be most significant from previous experience were selected as 'factors' in the DOE. Each of these factors was allowed to take one of three possible values, as shown in Table 3 (Z-stiff was chosen to be dependent on $X$-stiff in order to maintain a constant approach angle). All other parameters were fixed at levels typically observed on small European cars. For reference, the pedestrian leg-form knee height is defined to be 494 $\mathrm{mm}$ from the ground.

The orthogonal array chosen for the DOE was the M27 'probing' matrix. This allows all four of the three-level factors to be used while leaving the main effects and firstorder interactions 'clear' (i.e., not confounded with each other)

\section{CAE BUCK RESULTS}

A typical sequence of events is illustrated in Figure 7. Maximum tibia acceleration typically occurs between 5 and 10 milliseconds after initial contact with the bumper system. Maximum bending angle typically occurs 10 to 15 milliseconds later.

For the DOE analysis to produce valid engineering guidelines, the average of the test results should be near the required target values (from the proposed legislation). The acceleration results of this CAE DOE were well distributed around the $150 \mathrm{G}$ target. However, the knee bend angles were centered around 20 degrees, five degrees higher than the target of 15 degrees. Because of this, the stiffener locations for the subsequent variable buck testing were changed to ensure well-balanced results.

The DOE analysis was performed as an ANOVA (Analysis of Variance) using Minitab. A significance criteria of $90 \%$ $(1.0-P>0.9)$ was used to evaluate the factors and interactions. This analysis indicated that all four factors were significant relative to the knee bend angle results. However, only two of the factors, K-Bump and K-Stiff, were significant for the acceleration results. In addition, none of the first-order interactions were found to be significant for either of the measured results.

The DOE analysis also consisted of viewing main effects plots to check for curvature in the responses and determine whether the ranges selected for the CAE model were appropriate to be used in the physical testing. From the main effects plots, it was observed that the stiffener stiffness (K-Stiff) was linear in both response variables. Also, K-Stiff was found to have opposite effects on the two measured results: Higher spoiler stiffness resulted in lower bend angle, but higher acceleration. Because of this, the K-Stiff factor levels were changed for the physical testing, based on further CAE optimization of this parameter.

Table 3: Parameter Levels in CAE DOE

\begin{tabular}{|c|c|c|c|c|}
\hline Factor & \multicolumn{3}{|c|}{ Levels } & Unit \\
& -1 & 0 & +1 & \\
\hline X-grille & - & 65 & - & $\mathrm{mm}$ \\
\hline H-bump & - & 140 & - & $\mathrm{mm}$ \\
\hline K-BUMP & 200 & 250 & 300 & $\mathrm{kPa}$ \\
\hline X-BUMP & 70 & 110 & 150 & $\mathrm{~mm}$ \\
\hline Z-bump & - & 445 & - & $\mathrm{mm}$ \\
\hline K-STIFF & 0 & 1.75 & 6.25 & $\mathrm{kN}$ \\
\hline X-STIFF & -30 & -15 & 0 & $\mathrm{~mm}$ \\
\hline Z-stiff & 265 & 270 & 275 & $\mathrm{~mm}$ \\
\hline
\end{tabular}




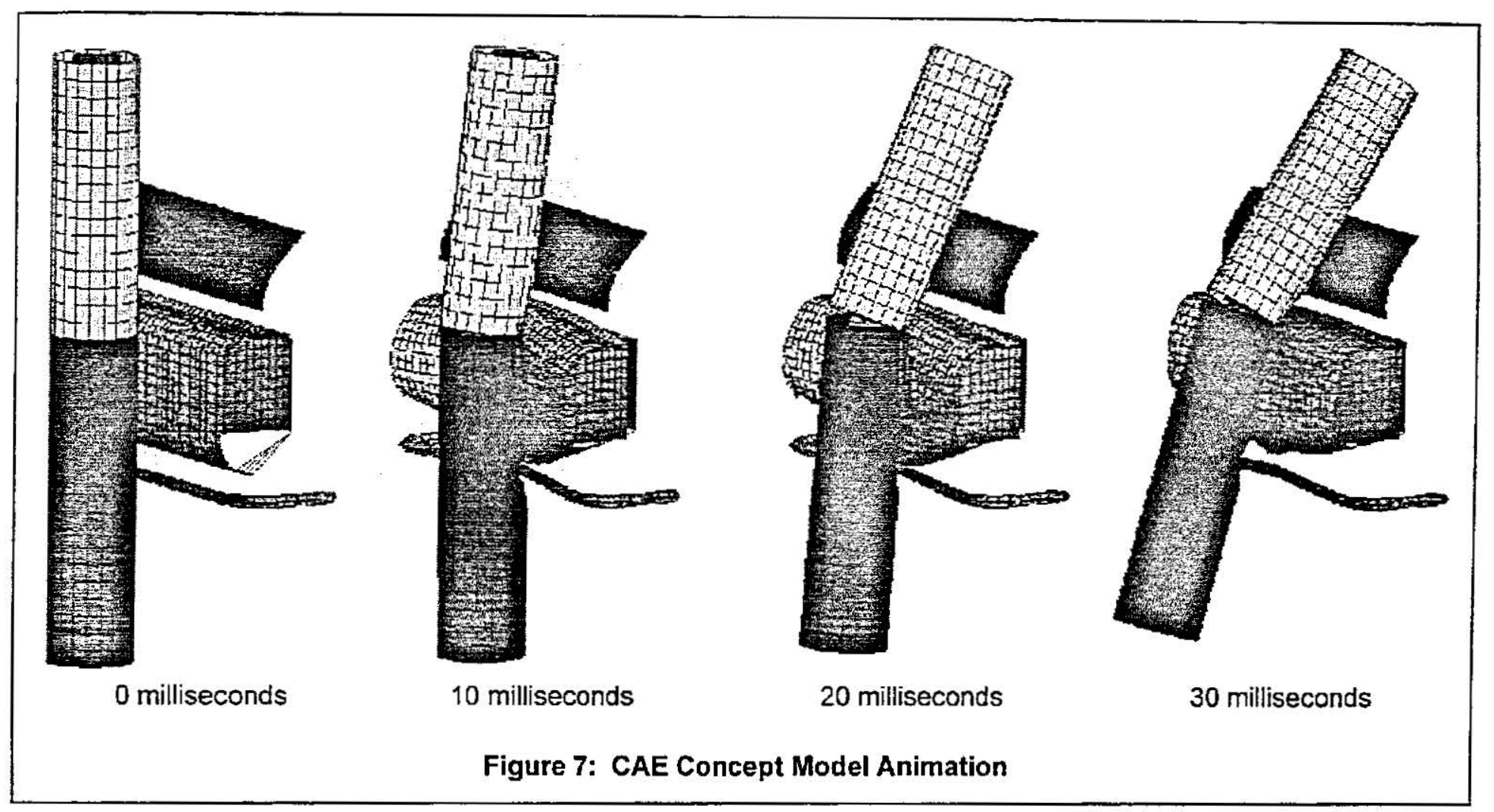

\section{VARIABLE BUCK TESTING}

The test setup, the experimental design, and the DOE results for the physical test series using the Variable FrontEnd Buck are presented in this section.

\section{TEST RIG CONFIGURATION}

The test setup consisted of the Variable Front-End Buck rigidly mounted to a steel bed-plate placed in front of a Bendix Impactor ${ }^{(a)}$. There was a carriage attached to the impactor to support the pedestrian leg-form during the initial acceleration of the cylinder. The carriage was stopped after the initial acceleration was complete, allowing the leg to travel the last $0.6 \mathrm{~m}$ to the Variable Front-End Buck in free fight at $40 \mathrm{~km} / \mathrm{h}$.

A schematic of the Buck was shown in Figure 2. A posttest photograph of the Buck is shown in Figure 8. Sliding attachments and spacer blocks were used for the bumper and stiffener vertical and longitudinal positioning. The plastic grille assembly was attached only at the outboard edges of the Buck, allowing it to bend during the impact. The hood inner panel was attached at the centerline of the buck to simulate a hood latch. The bumper and stiffener components were replaced after each impact. The hood and grille were inspected after each impact and replaced if any structural damage was found.

\footnotetext{
a Bendix Impactor - a hydraulic open loop actuator used as a guided mass accelerator to push 9 to 340 $\mathrm{kg}$ from 8 to $80 \mathrm{~km} / \mathrm{h}$.
}

\section{DESIGN OF EXPERIMENT (DOE) APPROACH}

In order to minimize the number of experimental runs, a Screening DOE approach was used. The key questions to be answered by the DOE were:

- Which factors are most critical to the pedestrian legform impactor performance?

- Which factors have a non-linear relationship to the responses?

- What are the best settings for the critical factors?

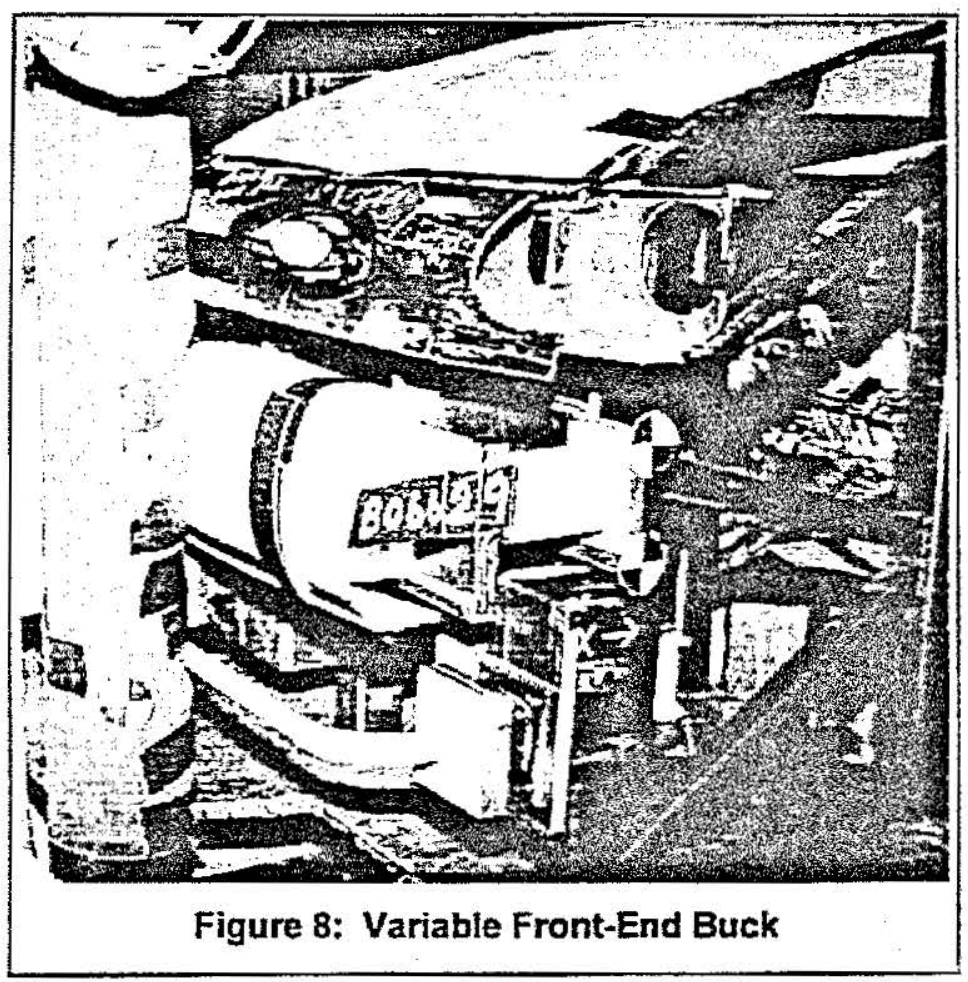


The second question led us to adopt an M18 experimental design, allowing more than two levels for each factor. This design. shown in Table 4, spreads interaction terms across many columns to minimize their influence on a single main effect. Therefore main factor interactions cannot be studied directly with this matrix. This was not a concern for this DOE, since these interactions were found to be weak in magnitude during the CAE Buck analysis.

A total of six factors were changed during the testing. This left two columns of the matrix empty to establish the level of noise in the system. Also, one repeat run was performed, to establish the repeatability of the experiment. The six factors and their settings are listed in Table 5 . These settings were chosen based on the CAE DOE results. In particular, note that $\underline{X}$-Stiff has been extended to move the stiffener in front of the bumper leading edge $(+30)$. Also, K-Stiff was reduced to two levels since its response was found to be linear in the CAE DOE. These wo levels were chosen in an attempt to achieve Knee Bend Angle results centered around the target of 15 degrees. While reading this table, recall that the leg-form knee height is $494 \mathrm{~mm}$ from ground.

\section{ANALYSIS OF RESULTS}

The experimental results were analyzed using the

Table 4: M18 DOE Matrix

\begin{tabular}{|c|c|c|c|c|c|c|c|c|}
\hline \multirow{2}{*}{ RUN } & \multicolumn{7}{|c|}{ COLUMN } \\
\cline { 2 - 9 } & 1 & 2 & 3 & 4 & 5 & 6 & 7 & 8 \\
\hline 1 & -1 & -1 & -1 & -1 & -1 & -1 & -1 & -1 \\
\hline 2 & -1 & -1 & 0 & 0 & 0 & 0 & 0 & 0 \\
\hline 3 & -1 & -1 & +1 & +1 & +1 & +1 & +1 & +1 \\
\hline 4 & -1 & 0 & -1 & -1 & 0 & 0 & +1 & +1 \\
\hline 5 & -1 & 0 & 0 & 0 & +1 & +1 & -1 & -1 \\
\hline 6 & -1 & 0 & +1 & +1 & -1 & -1 & 0 & 0 \\
\hline 7 & -1 & +1 & -1 & 0 & -1 & +1 & 0 & +1 \\
\hline 8 & -1 & +1 & 0 & +1 & 0 & -1 & +1 & -1 \\
\hline 9 & +1 & +1 & +1 & -1 & +1 & 0 & -1 & 0 \\
\hline 10 & +1 & -1 & -1 & +1 & +1 & 0 & 0 & -1 \\
\hline 11 & +1 & -1 & 0 & -1 & -1 & +1 & +1 & 0 \\
\hline 12 & +1 & -1 & +1 & 0 & 0 & -1 & -1 & +1 \\
\hline 13 & +1 & 0 & -1 & 0 & +1 & -1 & +1 & 0 \\
\hline 14 & +1 & 0 & 0 & +1 & -1 & 0 & -1 & +1 \\
\hline 15 & +1 & 0 & +1 & -1 & 0 & +1 & 0 & -1 \\
\hline 16 & +1 & +1 & -1 & +1 & 0 & +1 & -1 & 0 \\
\hline 17 & +1 & +1 & 0 & -1 & +1 & -1 & 0 & +1 \\
\hline 18 & +1 & +1 & +1 & 0 & -1 & 0 & +1 & -1 \\
\hline & & & & & & \\
\hline
\end{tabular}

Table 5: Parameter Levels for Test DOE

\begin{tabular}{|c|c|c|c|c|}
\hline Factor & \multicolumn{3}{|c|}{ Levels } & Unit \\
& -1 & 0 & +1 & \\
\hline X-grille & - & 65 & - & $\mathrm{mm}$ \\
\hline H-bump & - & 140 & - & $\mathrm{mm}$ \\
\hline K-BUMP & 95 & 125 & 155 & $\mathrm{kPa}$ \\
\hline X-BUMP & 70 & 110 & 150 & $\mathrm{~mm}$ \\
\hline Z-BUMP & 420 & 445 & 470 & $\mathrm{~mm}$ \\
\hline K-STIFF & 1.75 & - & 4.00 & $\mathrm{kN}$ \\
\hline X-STIFF & -30 & 0 & +30 & $\mathrm{~mm}$ \\
\hline Z-STIFF & 240 & 270 & 300 & $\mathrm{~mm}$ \\
\hline
\end{tabular}

Response Surface Model (RSM) method in Minitab version 9.2. Two types of analysis were performed:

- Statistical significance was determined by calculating the coefficient of determination $\left(R^{2}\right)$ for each factor. Significance was defined to be greater than $90 \%$.

- Box-plots ${ }^{(2)}$ were produced to illustrate the effect of each factor on the results.

Applicability of the results is limited to the ranges of values which were tested. Some extrapolation is probably acceptable, but caution should be exercised.

Five factors were found to be significant for the maximum Knee Bend Angle. These factors and their statistical significance are listed in Table 6 . This table also includes an assessment of whether the response from that factor is essentially linear or non-linear. Figure 9 contains boxplots of the results for each significant factor. To focus on the trends rather than the absolute values, the overall Knee Bend average was subtracted out before plotting.

Table 6: Significant Factors for Knee Bend Angle

\begin{tabular}{|c|c|c|}
\hline FACTOR & SIGNIFICANCE & LINEAR? $^{-}$ \\
\hline K-Stiff & 0.99 & YES $^{(b)}$ \\
\hline X-Stiff & 0.99 & YES \\
\hline Z-Bump & 0.99 & YES \\
\hline X-Bump & 0.94 & YES \\
\hline Z-Stiff & 0.93 & NO \\
\hline
\end{tabular}

\footnotetext{
${ }^{a}$ Box-plot: A plot showing the mean and +1 - one standard deviation for each level of a given factor. The mean is shown as a horizontal line and a "box" extends above and below to the standard deviations. ${ }^{b} \mathrm{~K}$-Stiff was only tested at two levels. It is assumed to
} 

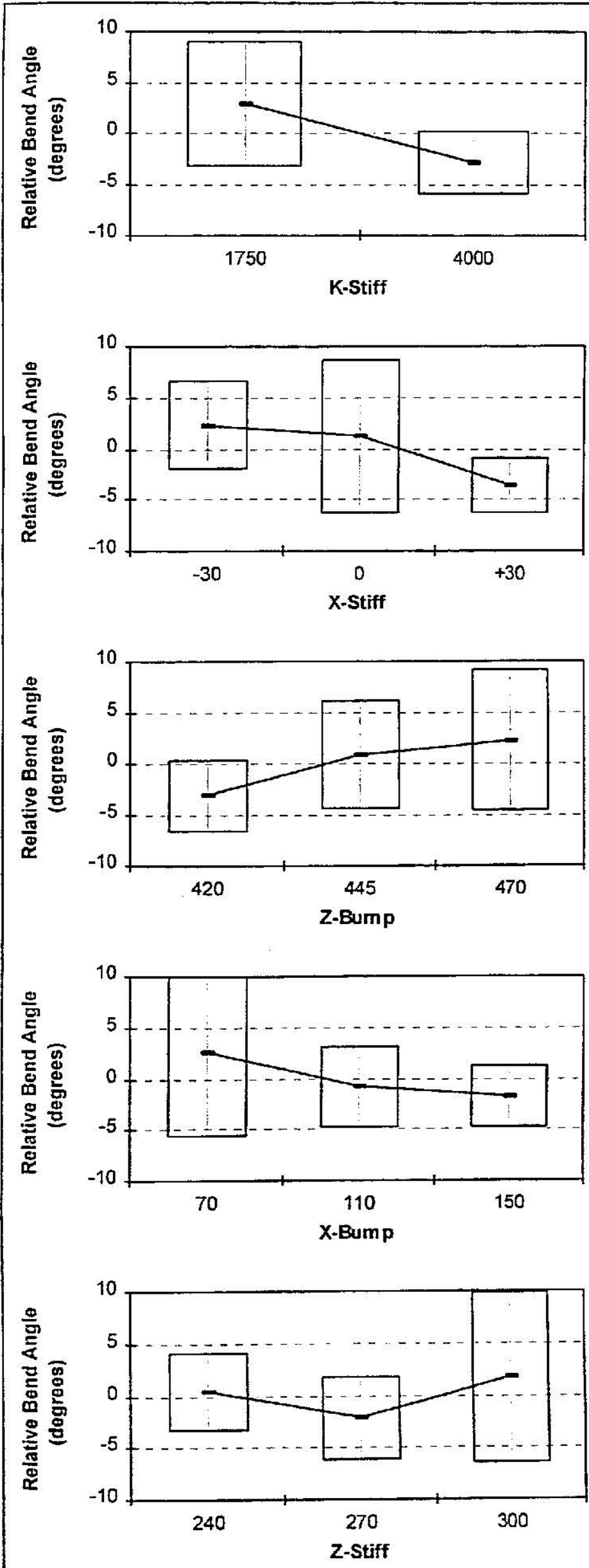

Figure 9: Significant Factors for Knee Bend Angle (plotted relative to overall test average)
Table 7: Significant Factors for Tibia Acceleration

\begin{tabular}{|c|c|c|}
\hline FACTOR & SIGNIFICANCE & LINEAR? \\
\hline X-Stiff & 0.98 & YES \\
\hline$X$-Bump & 0.92 & NO \\
\hline
\end{tabular}

Two factors were found to be significant for the maximum Tibia Acceleration. These factors are listed in Table 7. Figure 10 contains box-plots of the results for these factors. The overall Tibia Acceleration average was subtracted out before plotting.

\section{CAE CORRELATION}

A study is currently underway to correlate the CAE Concept Model results to the Variable Front-End Buck test results. Preliminary results from this study have indicated the difference in mass properties (especially tibia C.G.) noted in Table 2 has a significant effect on the knee bend angle results in the CAE Concept Model.

In addition, the correlation study has identified a significant concern with the specification of the knee ligament bending corridor. In an attempt to achieve correlation between the CAE and test results, the knee ligament bending curve used in the CAE model was varied to correspond to (a) the top of the corridor, (b) the bottom of the corridor, and (c) the actual curve generated from the ligaments used in the testing. These changes resulted in knee bend angles which were 10 degrees apart, from 9 to 19 degrees for a single configuration. This variation
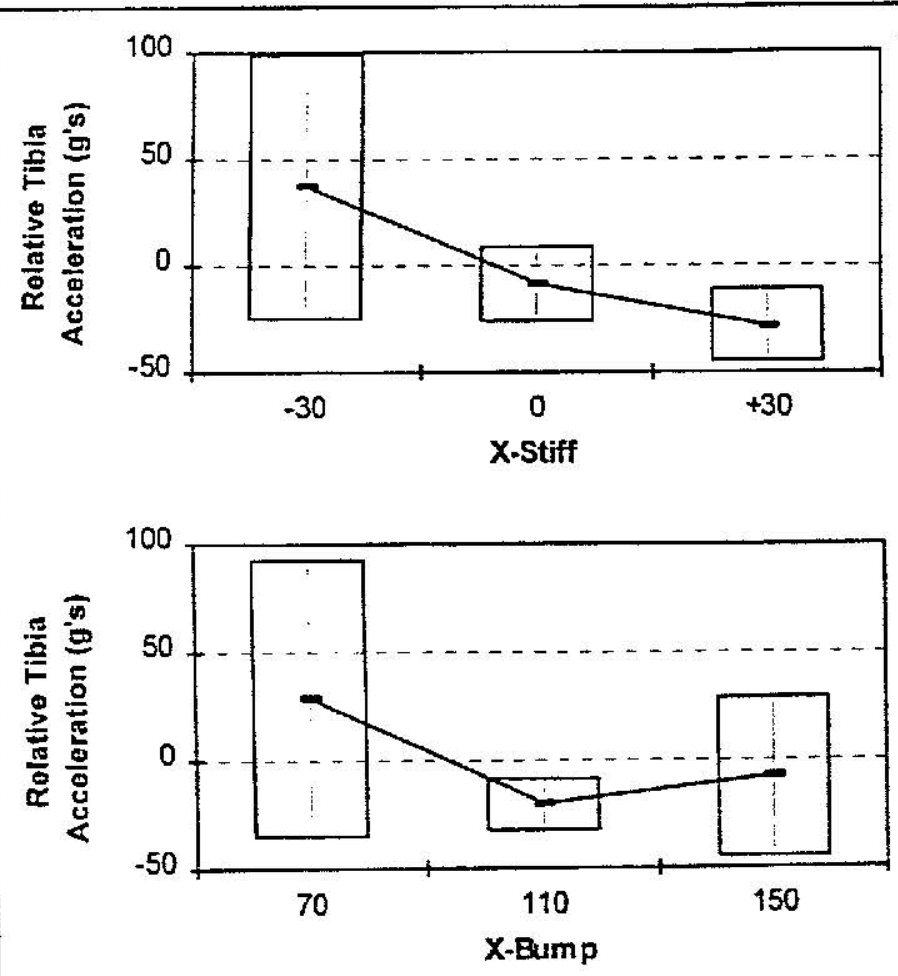

Figure 10: Significant Factors for Tibia Acceleration (plotted relative to overall test average) 
indicates that the exact bending curve of the knee ligaments used in a test will significantly affect the bend angle results, even if the ligaments fall within the specification.

\section{DISCUSSION}

Table 6 and Table 7 indicate that the location and stiffness of the lower stiffener are the most significant of the investigated factors. In addition, the bumper foam height and depth play an important, though lesser, role. These results are in agreement with the recommended bumper designs previously reported ${ }^{[5-16 ;}$, with the exception of the bumper foam stiffness, which was not found to be significant within the ranges tested in this study. The current work adds quantified results to the previous recommendations-identifying the relative importance of each factor and its effects.

At this point it is important to re-iterate that the results presented are only valid in the ranges tested. In particular, the experimental results suggest that bumper foam stiffness is not a significant parameter in pedestrian leg impact. This observation is only applicable within the stiffness ranges tested (Table 5) - from 0.5 to 1.0 times the stiffness of a typical European bumper energy absorber. The authors believe that the ranges tested for this parameter were too close to identify its critical nature which will likely appear when the stiffness is increased or decreased outside of this range.

As fat as the authors are aware, the lower stiffener is a new component not used on current vehicles. Because of this. any issues associated with its addition to the vehicle need to be identified. Several concerns become apparent when considering the addition of this stiff component projecting ahead and below the bumper.

- The stiffener may increase the likelihood of injury to the tibia, fibula, or ankle joint. This possibility has not yet been investigated since the proposed legislation offers no method for measuring ankle or lower tibia injury (the acceleration is measured near the top of the (itia segment on the leg-form).

- The stiffener may increase the velocity of the thigh/pelvis and head impacts by increasing the speed of the pedestrian's rotation around the vehicle's
leading edge.

- High-speed impact performance may be affected, depending on the altachment points and stiffness of
the stiffener.

- Low-speed damageability perfornance will be affected since the stiffener will likely contact some obstacles before the bumper.

- The overall vehicle length will most likely increase, potentially forcing changes to manufacturing plants or
shipping operations.
- This study focused on centerline impacts in controlled conditions. Designing a stiffener with the same stiffness characteristics across the entire width of a vehicle remains an open issue.

Three issues associated with the bumper foam depth and position are:

- Deeper bumper foams may affect high-speed impact performance by changing the initial vehicle deceleration seen by the airbag sensor.

- Lower bumper heights may affect ECE-42 performance by moving the bumper system below the specified impact height.

- Deeper bumper foams will result in an increase in the vehicle length, potentially forcing changes to manufacturing plants or shipping operations.

In addition, any of the identified changes to the bumper system will certainly result in increased cost and weight to the vehicle designed to meet the proposed pedestrian legform impact requirements.

\section{CONCLUSIONS}

There are several styling, packaging, and stiffness factors in the design of a vehicle's front-end which influence pedestrian leg-form impact performance. The focus of this work was to determine which of several selected factors significantly affect the impact test resuits.

The paper reviewed the development of a standard proposing requirements for pedestrian leg impact. Previously published bumper design recommendations for pedestrian impact were presented, followed by a discussion of issues associated with the two current proposed leg-form impactors.

The methodology utilized a CAE leg impactor model and front-end concept model in addition to a Variable FrontEnd Buck to investigate the effects of various front-end design parameters on pedestrian leg-form impacts. Six front-end factors were investigated in a DOE using the buck and CAE concept model. The trends identified from the experimental results were found to be consistent with CAE results. In addition, during the CAE correlation, the wide knee ligament certification corridor was found to result in a potentially non-robust measurement of lateral knee bend angle.

The key bumper design factors associated with pedestrian leg-form impact performance were identified. Issues associated with introducing the vehicle front-end design changes suggested by the experimental results were identified for future study. 


\section{ACKNOWLEDGEMENTS}

The authors gratefully acknowledge the assistance of the following individuals in this work:

- Glenn Klecker, who had the initial idea of a Variable Front End Buck.

- Karin Rothacker, who heiped develop the 'Simplified Leg-form' and coordinated the Buck testing.

- Klaus-W. Huland of Bayer AG, who provided the foam samples used in the testing.

\section{REFERENCES}

1 Harris, J., Lawrence, G. L., Hardy, B. "Test Methods to Evaluate the Protection Afforded to Pedestrians by Cars." Transport Road Research Laboratories (TRRL) document WPNS/216, July 1991.

2 "Draft Proposal for a European Parliament and Council Directive Relating to the Protection of Pedestrians and Other Road Users in the Event of a Collision with a Motor Vehicle." European Commission document III/5021/96 EN, February 7, 1996.

3 Cesari, D., Alonzo, F., Matyjewski, M. "Subsystem Test for Pedestrian Lower Leg and Knee Protection." 1991 ESV Conference, Paper \# S3-0-08.

4 Lawrence, G.J.L., Hardy, B.J., Harris, J. "Bonnet Leading Edge Sub-System Test for Cars to Assess Protection for Pedestrians." 1991 ESV Conference, Paper \# S3-W-22.

5 Glaeser, K.-P. "Development of a Head Impact Test Procedure for Pedestrian Protection." 1991 ESV Conference, Paper \# S3-O-07.

6 Cesari, D., Bouquet, R., Caire, Y., Bermond, F. "Protection of Pedestrians Against Leg Injuries." 1994 ESV Conference, Paper \# 94-S7-0-02.

7 Sakurai, M., Kobayashi, K., Ono, K., Sasaki, A. "Evaluation Of Pedestrian Protection Test Procedure In Japan-Influence Of Upper Body Mass On Leg Impact Test." 1994 ESV Conference, Paper \# 94-S7-0-01.

a Ishikawa, H., Yamazaki, K., Ono, K., Sasaki, A. "Current Situation of Pedestrian Accidents and Research into Pedestrian Protection in Japan." 1991 ESV Conference, Paper \# S3-O-05.

9 Harris, J. "Proposals for Test Methods to Evaluate Pedestrian Protection for Cars." 1991 ESV Conference, Paper \# S3-O-06.

10 Aldman, B., Kajzer, J., Anderlind, T., Malmqvist, M., Mellander, $H$., Turbell, T. "Load Transfer from the Striking Vehicle in Side and Pedestrian Impacts." 1985 ESV Conference.

11 Cesari, D., Cavallero, C., Cassan, F., Moffatt, C. "Interaction Between Human Leg and Car Bumper in Pedestrian Tests." 1988 IRCOBI Conference.

12 Ishikawa, J., Kajzer, J., Ono, K., Sakurai, M. "Simulation of car impact to pedestrian lower extremity: Influence of different car-front shapes and dummy parameters on test results." 1992 IRCOBI Conference.

13 Fowler, J., Harris, J. "Practical Vehicle Design for Pedestrian Protection." 1982 ESV Conference.
14 Dickison, M. "Development Of Passenger Cars To Minimize Pedestrian Injuries." 1996 SAE Conference, Paper \# 960098.

15 Kajzer, J., Aldman, B., Mellander, H., Planath, I., Jonasson, K. "Bumper System Evaluation Using an Experimental Pedestrian Dummy." 1989 ESV Conference.

16 Nagatomi, K., Akiyama, A., Kobayashi, T. "Bumper Structure for Pedestrian Protection." 1996 ESV Conference, Paper \# xxx.

17 "Regulation \# 42: Uniform Provisions Concerning the Approval of Vehicles With Regard to Their Front and Rear Protective Devices (Bumpers, etc.)." United Nations Economic Commission for Europe (ECE) Inland Transport Committee Agreement, March 24, 1980.

${ }^{18}$ Faerber, E. "Legform impact tests to evaluate the TRL legform impactor for the EEVC WG10 test procedure for car related pedestrian protection." BASt report, Bergisch Gladbach, December, 1995. 